\title{
RESPONSIVIDADE E ADAPTABILIDADE: ESCOLHAS PARA A TRANSPOSIÇÃO GRÁFICA DE UM AMBIENTE EDUCACIONAL DE DESKTOP PARA MOBILE
}

\author{
BRASÍLIA/DF MAIO/2018
Daniela Fontinele Botelho - AntBuzz - fontinele@gmail.com
Laura Gris Mota - AntBuzz - lauragris@antbuzz.net \\ Tipo: Relato de Experiência Inovadora (EI) \\ Categoria: Métodos e Tecnologias \\ Setor Educacional: EDUCAÇÃO CONTINUADA EM GERAL
}

\begin{abstract}
RESUMO
O crescente uso dos smartphones no país fez com que os sites começassem a se preocupar com a adaptação dos seus conteúdos para as telas pequenas. Esse movimento deu início ao conceito de responsive web design (RWD) - quando uma página web tem aparência dinâmica, reposicionando e redimensionando seus elementos para encaixar numa tela de smartphone. O campo da educação online não poderia deixar de dar atenção para esses ajustes, visto que seu canal de transmissão é a web. Esse artigo pretende ilustrar o processo conceitual de adaptação do layout de um ambiente educacional, originalmente criado para desktop, para a versão mobile. O relato vai partir da análise estrutural do ambiente desktop, sua decomposição e reconstrução na tela menor, mostrando que apenas o RWD não é suficiente para manter as características do ambiente educacional original e as soluções propostas para manter o continnum experiencial da educação.
\end{abstract}

Palavras-chave: mobile learning, design, responsividade, ambiente de aprendizagem, ux design 


\section{INTRODUÇÃO e OBJETIVOS}

A Pesquisa Brasileira de Mídia mostrou que a maior parte dos brasileiros utiliza os celulares como acesso principal à internet. $O$ crescente uso dos dispositivos de telas pequenas (mobiles) deu início ao conceito de responsive web design (RWD), cujo foco é fazer com que os sites se comportem de maneira ideal, independente do tamanho de tela.

Contudo, a responsividade, como resultado final, apenas reorganiza os elementos para uma melhor distribuição visual e não leva em conta as diferenças entre telas e dispositivos. Além do tamanho, que refletiu nos menus, por exemplo, a ausência do teclado físico e da interação por clique do mouse, em tablets e smartphones, são fatores que impactam na experiência do usuário na interação e compreensão do conteúdo ao qual ele é exposto, sendo necessária uma adaptação que leve em conta não só a distribuição dos elementos já existentes mas também o redesenho de forma ampla, para contemplar as características próprias dos dispositivos móveis.

Para um ambiente web ser adaptado para dispositivo móveis é preciso repensar não só a distribuição dos elementos gráficos, mas seu redesenho, bem como a arquitetura de informação, a linguagem dos conteúdos e as formas interação. O conjunto design gráfico e de interação, arquitetura de informação e linguagem define a forma como o site vai ser percebido pelo usuário e como será sua experiência.

Ambientes educacionais construídos para telas grandes, quando da sua transposição para dispositivos móveis, precisam replicar a experiência de aprendizagem do aluno. $O$ objetivo deste relato é ilustrar o processo de adaptação do layout de um ambiente educacional, originalmente criado para desktop, para a versão mobile. O relato vai partir da análise estrutural do ambiente desktop, sua decomposição e reconstrução na tela menor, mostrando que apenas o RWD não é suficiente para manter as características do ambiente educacional original e as soluções propostas para manter o continnum experiencial da educação.

\section{REFERENCIAL TEÓRICO}

A Pesquisa Brasileira de Mídia aponta que mais de $72 \%$ das pessoas utilizam o celular como o acesso principal à internet (IBOPE, 2016). A mobilidade e a facilidade de conexão mudaram inclusive a relação das pessoas com esses dispositivos. Dados da pesquisa Consumers in the Micro-Moments (GOOGLE, 2017) mostram que 29\% dos usuários de smartphone vão sair do site ou do aplicativo se ele não satisfizer suas 
necessidades - e os usuários “(...)esperam poder obter o que precisam imediatamente e à sua maneira." (GOVE, 2018). As novas formas de relacionamento promovidas pela presença da tecnologia promoveu novos tipos de relações sociais e apresentou para o campo da educação novos desafios (RANGEL-S e colab., 2016). Um deles é a forma de levar os ambientes educacionais para as telas pequenas.

O movimento de redesenho de sites, para permitir que os mesmos pudessem ser acessados nas telas pequenas, deu origem ao o conceito de responsive web design (RWD), que "permite aplicativos da Web adaptar-se às características de diferentes dispositivos, como tamanho da tela que é importante para a navegação móvel" (WIENER e colab., 2015). O design responsivo é, inclusive, um padrão recomendado pelo Google e um dos fatores determinantes para exibição do site no seu mecanismo de busca - sites não responsivos não aparecem em resultados de buscas feitas por smartphone. Tecnicamente, o RWD é possível com o uso da linguagem CSS (Cascading Style Sheets), que cria aparências dinâmicas para páginas web. O CSS aplica estilos na página web que definem a distribuição adequada dos elementos da página, com base no tamanho da tela ou no tipo de dispositivo.

Porém, devido à diferença de contexo, a responsividade não garante uma equivalência entre ambientes. Wierner e colaboradores (2015) ressaltam que os elementos responsivos só podem ser aplicados quando o contexto da tela menor é exatamente o mesmo do site, sendo necessária a mudança de requisitos para manter os objetivos iniciais do ambiente. Com isso, a responsividade não pode ser a única solução para que um ambiente digital possa ser transposto de telas grandes para telas pequenas.

Não apenas o tamanho da tela, mas também os fatores de interação entre o usuário e o conteúdo mostram que só a responsividade não atende a essa transposição. Budiu (2015) destaca que, no dispositivo móvel, a digitação se o teclado físico, por exemplo, é feita pelo toque na tela e, por isso divide espaço de visualização e atenção. Questões como essa devem ser levadas em conta quando do redesenho para mobile. Outros fatores como variação na qualidade da conexão de internet, além da troca do clique do mouse por toques e gestos também são pontos que diferenciam o mobile de outros dispositivos (BUDIU, 2015) e são importantes no redesenho do ambiente.

A necessidade de adaptação entre ambientes ultrapassa questões de funcionalidades. Pesquisas mostraram que leitura de textos simples não apresenta diferenças quando realizada em telas grandes ou pequenas. Ao contrário, quanto mais complexo o texto, mas difícil se torna a leitura em telas menores. Portanto, é preciso estar atento, também, à adaptação da linguagem para esse formato (MEYER, 2016), visto que ambiente 
educacional deve ser fluido e seu conteúdo precisa estabelecer uma conversa com o aluno (MATTAR, 2014).

A atenção na adaptação de ambientes educacionais online para ser visualizado em telas pequenas cresce em importância à medida que os objetivos educacionais e de aprendizagem definidos precisam ser preservados e garantidos em ambas situações, assegurando o continnum experiencial do processo educacional. $O$ trabalho nessa direção é multidisciplinar pois, no campo de atuação do design gráfico e digital, esses profissionais ainda não foram preparados para produção de materiais de educação a distância com foco na aprendizagem (MATTAR, 2014).

\section{PROCEDIMENTOS METODOLÓGICOS}

Para ilustrar a necessidade de adaptação de um ambiente de aprendizagem para mobile foi utilizado o estudo de um ambiente construído para um curso da área de saúde, estruturado originariamente, para navegação em telas de desktop. A equipe envolvida no processo contou com design gráfico e design de experiência (educacional, de navegação e de comunicação). O desenho original do ambiente era horizontal, com menu em arco e navegação também horizontal - não possível a responsividade dos elementos na posição vertical - posição padrão dos smartphones (Figura 1). A quantidade de conteúdo, assim como os microtextos dos botões não permitiam a redistribuição e redimensionamento simples dos elementos. Assim, a responsividade não atendia como única solução na transposição (Figura 2), pois não permitia a disposição correta do conteúdo educacional.

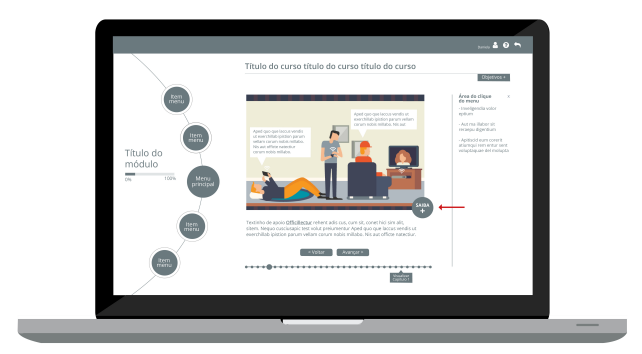

Figura 1 - Menu desenhado para desktop 


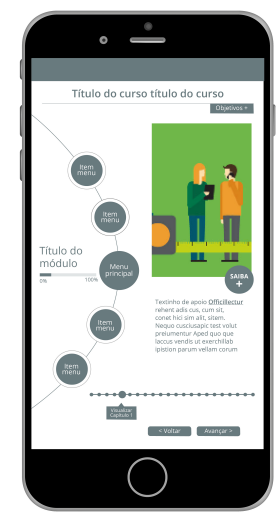

Figura 2 - Menu quando usada apenas a solução RWD

Após identificada a impossibilidade de utilização apenas do design responsivo para a transposição do curso, o primeiro passo foi desconstruir os elementos base do ambiente, processo que levou em conta o conteúdo disponível no elemento e sua característica principal - menu ou outro elemento do ambiente. Entendeu-se como menu todo o elemento que cujo objetivo era levar a outro conjunto de elementos e como componentes os conteúdos isolados. A desconstrução foi necessária para garantir, no processo de adaptação, um dos princípios mais importantes do design: hierarquia visual. $\mathrm{Na}$ criação é preciso definir prioridades que serão refletidas no layout. Todos os detalhes devem ser trabalhados, fontes, cores, tamanhos, contrastes e principalmente o que incluir, excluir e priorizar na sua execução.

Quanto menos distrações visuais o usuário encontrar mais naturalmente focado ele vai estar enquanto navega em um ambiente (WROBLEWSKI, 2008). A hierarquia visual ajuda que um conteúdo seja apresentado com a sua devida importância de acordo com - local que ele é colocado na tela e de acordo com o seu design. A interface tem que ajudar o usuário a estabelecer uma hierarquia entre um conteúdo de maior importância e outro de menor importância. A consistência dos elementos é fundamental na criação do layout, a harmonia entre eles causa um impacto positivo tendo como consequência uma experiência agradável tanto em desktop quanto em mobile. Além disso, "expressar hierarquias é um processo ativo, investigativo e capaz de gerar resultados visuais dinâmicos" (LUPTON et PHILLIPS, 2006). Assim, no processo, foram identificados quatro tipos de menus e três tipos de componentes, a saber: menu principal (identificação do curso e retorno ao ponto de início); menu de acesso contínuo (conteúdo para acesso durante o aprendizado (p.ex. para apoio a tomada de decisão); menu de acesso único (acesso pré ou pós curso (p. ex. informações sobre o curso - objetivos e ficha técnica - e material de apoio ao curso); e menu de retorno - função: acesso à página inicial do ambiente virtual de aprendizagem (AVA). 
Os componentes identificados foram: conteúdo do curso (conteúdo educacional para promover o atingimento dos objetivos de aprendizagem - leituras, vídeos, material interativo, avaliações entre outros); Saiba mais (apresentar conteúdo complementar de acesso imediato no ambiente do curso); e material de apoio (apresentar um banco de recursos para consulta e/ou uso posterior).

$\mathrm{Na}$ análise dos componentes, identificou-se diferentes gêneros dos conteúdos apresentados, os quais foram divididos em textual, imagético (foto, ilustração, gráficos), vídeo (multimodal ) e interativo (multimodal). Cada um dos conteúdos tinha um tipo de interação aluno-componente do ambiente. As interações e ações foram identificadas no conteúdo em desktop e sua solução mobile foi indicada. As ações identificadas foram: rolagem lateral (avançar/recuar no andamento do curso - no desktop: clique nos botões avançar/voltar pelas teclas de setas - no mobile?deslizar para direita-esquerda); rolagem vertical (ver conteúdo abaixo da dobra da tela - no desktop: barra de rolagem lateral e teclado - no mobile: deslizar para cima-baixo); selecionar elemento (escolher alternativa nas questões de avaliação - no desktop: clique do mouse - no mobile: toque); confirmar escolhas (confirmar respostas das avaliações - no desktop: clique do mouse - no mobile: toque); e zoom (aumentar imagem ou texto - no desktop: ferramenta do navegador - no mobile: movimento de pinça dos dedos).

\section{APRESENTAÇÃO E DISCUSSÃO DOS RESULTADOS}

Após a desconstrução dos elementos, a reconstrução do ambiente para mobile se deu com as seguintes premissas: (i) respeitar a identidade visual existente, (ii) manter as estratégias pedagógicas para alcance dos objetivos de aprendizagem e (ii) otimizar a usabilidade no novo ambiente. Três questões foram consideradas críticas e ilustram as necessidades de adaptação. Foram elas: o menu, o material do Saiba mais e o conteúdo em formato história em quadrinhos (multimodal: texto/imagem).

Conforme apresentado na Figura 1 e Figura 2, a solução da responsividade não foi suficiente para garantir o desenho do curso em mobile. Assim, a primeira adaptação foi trazer o menu em forma de arco para um desenho circular, a fim de manter a característica de cada item do menu e preservar a uniformidade do layout, fazendo com que mesmo que o aluno navegue no desktop ou no mobile ele tenha a sensação unidade visual entre os dois ambientes. Para que a navegação em mobile ficasse fluida, o menu foi separado do contexto do curso, ficando ativo somente quando necessário e não visível durante toda a navegação (Figura 3).

Percebe-se, que todos os elementos do menu foram mantidos, com atenção à 
redistribuição dos mesmos num layout vertical, sem perder as características do desenho. Para dar uma uniformidade melhor o item "Objetivos" também foi deslocado para o menu do mobile, ajudando a limpar mais ainda a tela principal onde o curso acontece.

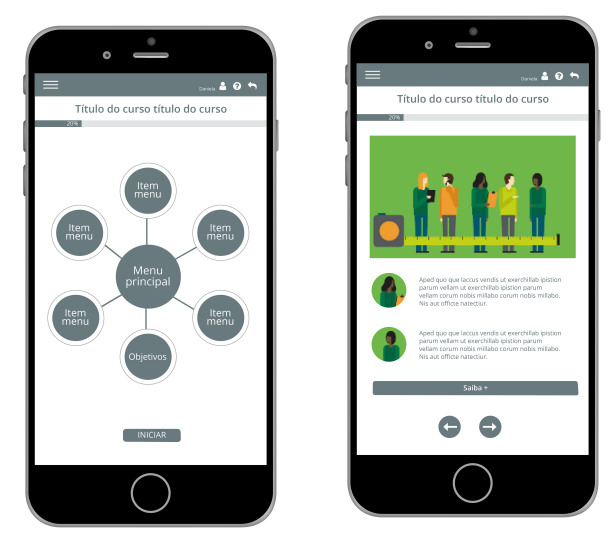

Figura 3 - Tela do menu adaptada para mobile separada do conteúdo principal

A segunda adaptação foi a apresentação do conteúdo Saiba mais (Figura 4), que no desktop aparece sempre no canto inferior direito da ilustração. O desenho desse botão foi feito para que o conteúdo principal esteja sempre no centro da tela e a que não haja desvio de atenção do material principal e o material de visualização secundário. 0 conteúdo do Saiba Mais foi distribuído nas laterais para atender as normas de hierarquia de informação. Levando em conta todos os princípios de hierarquia visual, o botão do Saiba mais que estava destacado, mas não como item principal de visualização, teve que ser redesenhado em forma de rolagem (Figura 5) para que seu destaque não se sobrepusesse ao conteúdo principal.

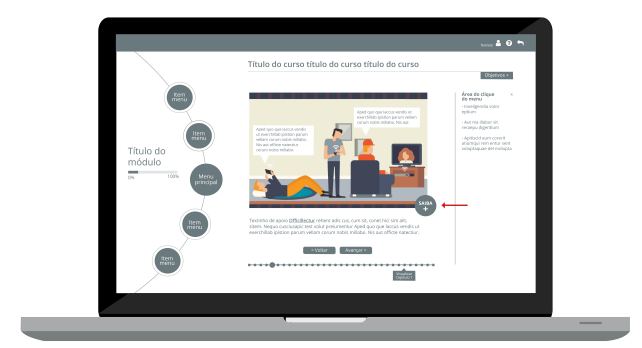

Figura 4 - Saiba Mais desenhado para desktop 


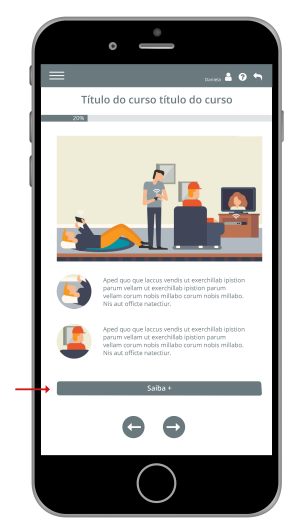

Figura 5 - Saiba Mais desenhado para mobile

A última adaptação ilustrativa desse relato diz respeito a necessidade de mudança no conteúdo em formato de história em quadrinho. O gênero, caracterizado por uma narrativa sequencial, baseada em imagens e com diálogos representados dentro de balões (LUCAS e colab., 2013), não é atendido pela responsividade, quando da transposição para uma tela menor. O quadrinho é, em sua natureza, um único elemento cuja linguagem visual e textual se complementam (Figura 6).

Para a reconstrução desse componente, foi necessária uma decomposição adicional: imagem e texto. Aplicações de texto em mobile devem garantir que a leitura seja confortável, no caso desse relato, se fosse mantido o layout do desktop somente com a redução do quadrinho com o texto dentro, ficaria inviável a leitura dos textos nos balões. Considerando a imagem como referencial do contexto de cena e o texto como conteúdo educacional, ambos precisavam estar representados na nova visualização.

Somente a aplicação do design responsivo nesse caso prejudicaria o aluno, então a adaptabilidade foi o recurso encontrado para esse problema. Os balões foram retirados da imagem principal e aplicado logo embaixo da ilustração principal, fazendo com que a ilustração ficasse mais limpa e com melhor leitura e o texto sem nenhuma interferência visual aplicado ao lado da imagem correspondente do personagem de fala (Figura 7).

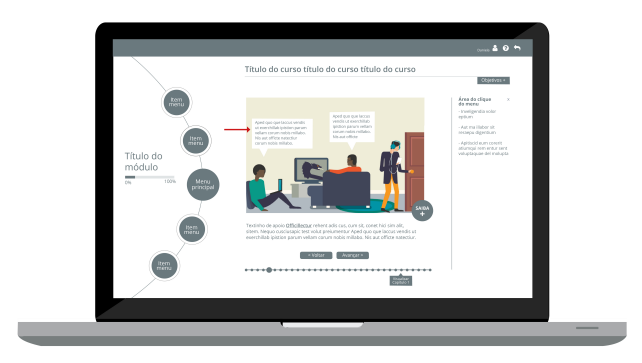


Figura 6 - Tela do curso em desktop - com história em quadrinho

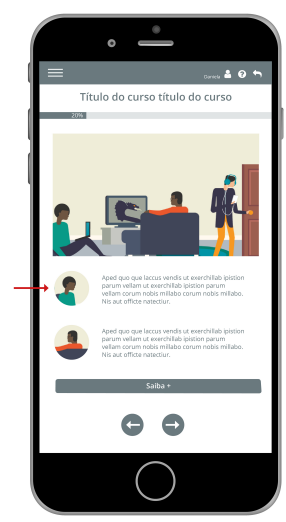

Figura 7 - Tela de história em quadrinho adaptada para mobile

\section{CONSIDERAÇÕES FINAIS}

Ambientes educacionais construídos para desktop, quando da sua transposição para dispositivos móveis, precisam mais do que os recursos de responsividade. Eles precisam de uma verdadeira adaptação ao novo contexto de tela pequena para que possam replicar a experiência de aprendizagem por meio de mensagens visuais que fiquem na memória e criem conexões futuras, estimulando o processo de educação contínua (MATTAR, 2014).

Logo, o desafio é garantir e preservar os objetivos educacionais e de aprendizagem desenhados no ambiente original, sem perder a potência das mensagens visuais para educação. O processo de adaptação do ambiente passa, necessariamente, por uma desconstrução dos elementos e pela reconstrução dos mesmos, no contexto do novo dispositivo, o qual apresenta características diversas e, por vezes, incompatíveis com o conteúdo e as interações originais.

É importante ressaltar que, apesar do foco do relato ter sido a transposição dos elementos visuais, a necessidade de adaptação da linguagem textual faz parte do processo adaptação visto que a forma de comunicação desse espaço digital é resultado do conjunto das diferentes linguagens (textual, gráfica, audiovisual e tátil).

\section{REFERÊNCIAS}

BUDIU, Raluca. Mobile User Experience: Limitations and Strengths. Nielsen Norman Group, 19 Abr 2015. Disponível em: . Acesso em: 20 abr 2018. 
GOOGLE. How mobile brand experiences drive equity. Data Gallery. Disponível em: . Acesso em: 19 abr 2018.

GOVE, Jenny. O Que Torna um Site Móvel Bom? Disponível em: . Acesso em: 19 abr 2018. IBOPE. Pesquisa Brasileira de Mídia. . [S.I: s.n.], 29 Ago 2016. Disponível em: . Acesso em: 19 abr 2018.

LUCAS, Henrique Denis; ROSA, Rosane; FERNANDES, Cristini. História em quadrinhos: reflexões metodológicas. Revista de la Red Académica Ineroamericana de Comunicación, v. 4, n. 1, 2013. Disponível em: . Acesso em: 25 abr 2018.

MATTAR, João. Design Educacional: educação a distância na prática. 1. ed. São Paulo: Artesanato Educacional, 2014.

MEYER, Kate. Reading Content on Mobile Devices. Nielsen Norman Group, 11 Dez 2016. Disponível em: . Acesso em: 20 abr 2018.

RANGEL-S, Maria Ligia e colab. Autonomia e aprendizagem colaborativa em educação a distância na perspectiva do estudante-médico em um curso de saúde coletiva. Educação a distância em saúde coletiva - interfaces na formação profissional. 1. ed. Salvador, BA: EDUFBA, 2016. p. 129-148. TEXTOS MULTIMODAIS. In: ROJO, Roxane. Glossário Ceale. [S.I: s.n.], [S.d.]. Disponível em: . Acesso em: 26 abr 2018.

WIENER, Lucas; EKHOLM, Tomas; HALLER, Philipp. Modular Responsive Web Design using Element Queries. arXiv:1511.01223 [cs], arXiv: 1511.01223, 4 Nov 2015. Disponível em: . Acesso em: 25 abr 2018.

WROBLEWSKI, Luke. Communicating with Visual Hierarchy. . [S.I: s.n.]. Disponível em: . , 2008 